\title{
Influence of the Dissolved Oxygen Concentration in Artificial Seawater on the Corrosion Behavior of Q235 Mild Steel
}

\author{
P.R. Meng, Y. Chen, Z.L. Liu* \\ Department of Chemical Engineering and Safety, Binzhou University, Binzhou, Shandong 256600, \\ China \\ *E-mail: liuzhilei98@126.com
}

doi: $10.20964 / 2020.05 .45$

Received: 21 December 2019/ Accepted: 27 January 2020 / Published: 10 April 2020

The corrosion behaviors of Q235 mild steel at different immersion times in artificial seawater containing different concentrations of dissolved oxygen were investigated using electrochemical impedance spectroscopy (EIS), electrochemical noise (EN) techniques and scanning electron microscopy (SEM). EIS results suggest that the sum of the charge transfer resistance and film resistance decreases with increasing immersion time and concentration of dissolved oxygen. A new electrochemical parameter $C_{A E}$, which represents the electrochemical reaction rate, is proposed and applied to evaluate the effect of dissolved oxygen concentration on the corrosion resistance and corrosion mechanism. The value of $C_{A E}$ initially increases with immersion time and later decreases with prolonged testing time. The sum of the charge transfer resistance and film resistance shows the opposite variation trend with that of $C_{A E}$ during the initial immersion times. Moreover, the observed morphologies of the Q235 mild steel surface agree well with the variation trend of $C_{A E}$ at different dissolved oxygen concentrations. The above results reveal a new criterion to monitor the corrosion resistance and surface morphology in situ using an EN technique.

Keywords: mild steel; dissolved oxygen; artificial seawater; electrochemical noise

\section{$\underline{\text { FULL TEXT }}$}

(C) 2020 The Authors. Published by ESG (www.electrochemsci.org). This article is an open access article distributed under the terms and conditions of the Creative Commons Attribution license (http://creativecommons.org/licenses/by/4.0/). 